\title{
Locomotion of a Running Quadruped Robotic System
}

Bradley Savon

University of South Florida

\author{
Advisors: \\ Masahiko Saito, Mathematics and Statistics \\ Luther Palmer III, Computer Science \& Engineering \\ Problem Suggested By: Luther Palmer III
}

Follow this and additional works at: https://digitalcommons.usf.edu/ujmm

Part of the Mathematics Commons

UJMM is an open access journal, free to authors and readers, and relies on your support:

Donate Now

\section{Recommended Citation}

Savon, Bradley (2010) "Locomotion of a Running Quadruped Robotic System," Undergraduate Journal of Mathematical Modeling: One + Two: Vol. 2: Iss. 2, Article 10.

DOI: http://dx.doi.org/10.5038/2326-3652.2.2.10

Available at: https://digitalcommons.usf.edu/ujmm/vol2/iss2/10 


\title{
Locomotion of a Running Quadruped Robotic System
}

\begin{abstract}
Very little is known about the locomotion of quadruped robotic systems. In Latin, the term quadruped means 'having four feet'. The robotic system analyzed in this project was a software simulation program modeled after a horse. Simulation data was recorded to resolve the relationship between foot position and impulses required to accelerate or to decelerate the system while trotting. These sets of data were then analyzed in MATLAB to produce graphical representations which allowed for a better understanding of the robot's motion in the simulation environment. A function was fit to the graph of discrete data values measured in the simulation. This function provided a model of the necessary ground reaction forces and foot position at touchdown of the system.
\end{abstract}

\section{Keywords}

Robotics, Impulse Momentum Theorem, Touch Down Forces

Creative Commons License

(c) (i) (9)

This work is licensed under a Creative Commons Attribution-Noncommercial-Share Alike 4.0 License. 


\section{TABLE OF CONTENTS}

Problem Statement

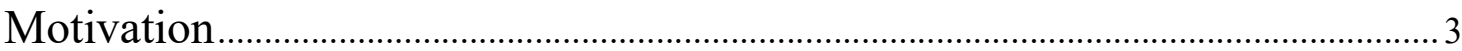

Mathematical Description and Solution Approach .....................................................

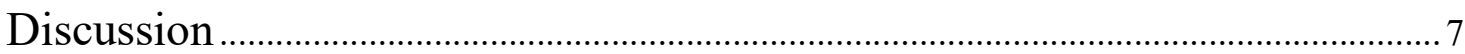

Conclusion and Recommendations .......................................................................

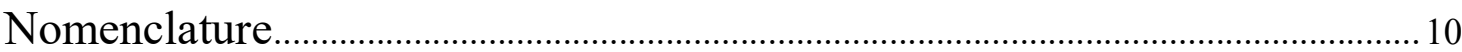

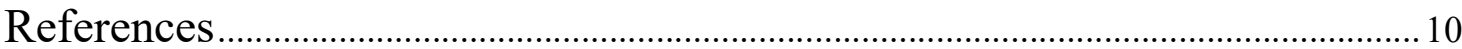

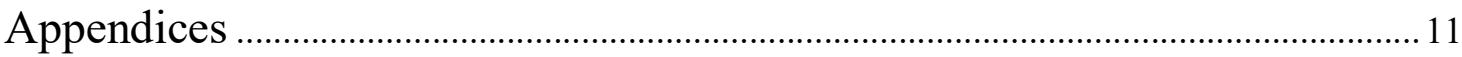




\section{PROBLEM STATEMENT}

As suggested by Luther Palmer III

Specifically, this project seeks to better predict the leg forces that need to be generated during the period that a foot is in contact with the ground. Ground reaction forces can be measured in simulation. Integration of these forces with respect to time, or impulses, provides the resultant forces on the system during the stance phase of a leg. The impulses are largely dictated by the fore-aft location of the foot with respect to its hip at the initial point of contact (touchdown). The task given was to resolve the relationship between foot position at touchdown and the resulting impulse so as to analytically solve for the desired touchdown position of the foot, given a desired acceleration or deceleration of the robotic system.

\section{MOTIVATION}

Biological systems provide engineers with useful information on locomotion in an unknown environment. Quadruped robotic systems that mimic biology are valuable in space exploration, military missions, and search and rescue operations. To better understand the movement of biological systems, ground reaction forces and leg touchdown angles are measured. The objective for the project is to gain insight into the dynamics related to a quadrupeds' mobility. The implications of these findings will allow for further research into trotting algorithms and the locomotion of robotic systems.

The Biomorphic Robotics Laboratory (BRL) at the University of South Florida seeks to build legged robotic systems inspired by human and animal morphology. As biologists provide insight into animal biomechanics, the BRL hopes to build experimental models that can be used 
to test biological hypotheses and further increase the understanding of these biological systems. The models represent the essence of animal locomotion without the intricacies of individual animal morphology.

\section{MATHEMATICAL DESCRIPTION AND SOLUTION APPROACH}

For the remainder of this paper we take the following conventions. Let

$$
\left\{\begin{array}{lll}
\mathrm{I} & \text { Impluse } & \mathrm{kg} \cdot \mathrm{m} \\
p & \text { Momentum } & \mathrm{kg} \cdot \mathrm{m} / \mathrm{s} \\
\mathrm{m} & \text { Mass } & \mathrm{kg} \\
v & \text { Velocity } & \mathrm{m} / \mathrm{s}
\end{array}\right.
$$

Impulse I, produced from touchdown to liftoff, is defined by

$$
I=\int_{\text {touchdown }}^{\text {liftoff }} F d t
$$

where $F$ is the applied force and $d t$ is an infinitesimal amount of time. From Newton's second law, force is related to momentum $p$ by

$$
F=\frac{d p}{d t}
$$

Substituting (2) in (1) yields

$$
I=\int_{\text {touchdown }}^{\text {liftoff }} \frac{d p}{d t} d t=\int_{\text {touchdown }}^{\text {liftoff }} d p=\Delta p
$$

which is known as the Impulse-Momentum Theorem. Momentum $p$ is the product of mass and velocity of an object, so $p=m v$ and

$$
\Delta p=m v_{f}-m v_{i}
$$

Substituting (4) in (3) yields 


$$
I=m v_{f}-m v_{i}=m\left(v_{f}-v_{i}\right)
$$

Our approach to the solution began by collecting data from the robot simulation environment. The data collected included the time, leg phases (touchdown, liftoff, flight, and transition), velocity forward ( $x$-direction), and the ground forces ( $x$-direction). The data was collected at a time step of 1 millisecond ( 0.001 seconds) during three phases of locomotion:

1. Decreasing velocity from 3 to $2.75 \mathrm{~m} / \mathrm{s}$,

2. Constant velocity of $3 \mathrm{~m} / \mathrm{s}$, and

3. Increasing velocity from 3 to $3.25 \mathrm{~m} / \mathrm{s}$.

The data was analyzed with the assistance of MATLAB software. The following MATLAB code displayed the ground reaction force curve with respect to time:

$$
\text { plot (time, groundF_x } \left.(:, 1)+\operatorname{ground} F_{-} x(:, 4)\right)
$$

The quadruped's right front (leg 1) and left hind (leg 4) legs move in unison, therefore it was necessary to sum the ground forces applied to both legs to get the total ground force applied for the step. This curve was shown in figure (2) as a dark blue solid line. The impulse, the integration of the ground force curve, shown in figure (2) was simply displayed with the following code.

$$
\text { area (time, } \left.\operatorname{ground} F_{-} x(:, 1)+\operatorname{ground} F_{-} x(:, 4)\right)
$$

Recalling that the time step is 1 millisecond, the MATLAB code which calculated the impulse was:

$$
\begin{aligned}
\text { Impulse }= & \operatorname{sum}\left(\operatorname{ground} F_{-x}(:, 1) . * 0.001\right)+\ldots \\
& +\operatorname{sum}(\operatorname{groundF} \times(:, 4) . * 0.001) .
\end{aligned}
$$


As displayed in equation (1), the impulse was calculated by taking the sum of the areas created by the product of the ground forces and brief intervals of time. The total impulse included the sum the impulse from both leg 1 and leg 4. For example, when the robot was increasing its velocity from 3 to $3.25 \mathrm{~m} / \mathrm{s}$ the following calculations applied.

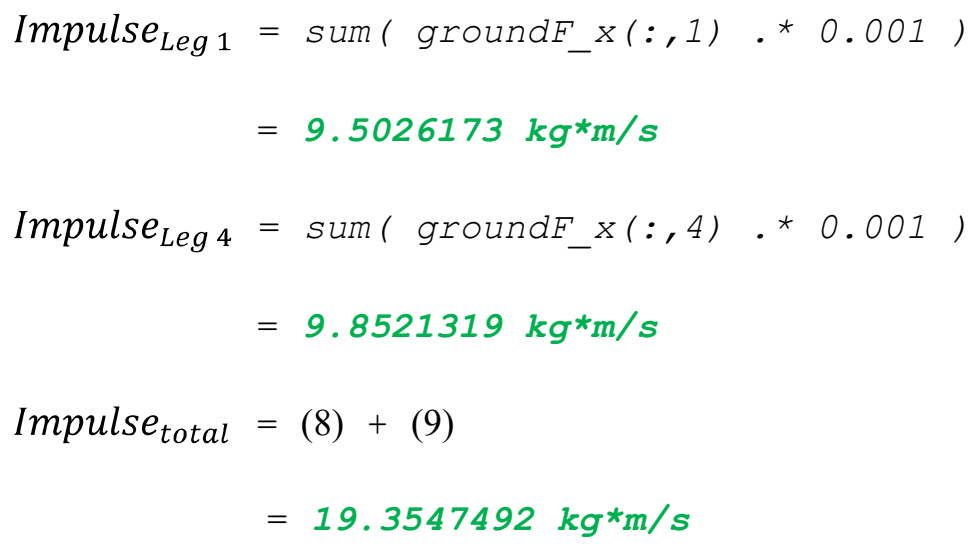

Equation (5) verifies these results. The mass of the simulated robot was $76 \mathrm{~kg}$. The initial velocity was $3 \mathrm{~m} / \mathrm{s}$ and the final velocity was $3.25 \mathrm{~m} / \mathrm{s}$.

$$
\begin{aligned}
I & =m\left(v_{f}-v_{i}\right) \\
& =76_{\mathrm{kg}}\left(3.25_{\mathrm{m} / \mathrm{s}}-3_{\mathrm{m} / \mathrm{s}}\right) \\
& =19_{\mathrm{kg} * \mathrm{~m} / \mathrm{s}}
\end{aligned}
$$

Taking the calculated result (10) and the theoretical result (11) allows for a comparison of percent error:

$$
\begin{aligned}
\% \text { Error } & =\left(\frac{\text { Actual }- \text { Theoretical }}{\text { Theoretical }}\right) 100 \\
& =\left(\frac{19.3547492-19}{19}\right) 100 \\
& =1.8671 \% .
\end{aligned}
$$


This small error can be attributed to rounding errors in the trotting algorithm and noise in the system. Similarly, the impulse can be calculated for constant and decreasing velocity. Figure 6 in Appendix B displays the virtual leg angle measured when the leg makes contact with the ground (touchdown).

To resolve the relationship between the impulse and touchdown positions, the total stance period was measured (touchdown to liftoff) as well as the time the virtual leg angle was greater than zero (touchdown to transition). This information led to a better understanding of the angle required to accelerate or to decelerate the system for an intended change in velocity.

The Batch Least Squares (BLS) method was used to approximate a function to the curve. The linear regression line used as the approximated function was

$$
Y=-22.29 x+111.6488
$$

The approximation provided a better understanding of the proper leg angle and impulse needed to accelerate or to decelerate the system greater than $0.25 \mathrm{~m} / \mathrm{s}$ (the current limitation on the trotting algorithm). It also allowed for the input of the desired velocity and outputs the percent of the stance period that the virtual leg angle is greater than zero. The calculations used to calculate and graph the approximation appear in Appendix A.

\section{DISCUSSION}

The objective of this project was to resolve the relationship between the foot position at touchdown and the resulting impulse so as to analytically solve for the desired touchdown position of the foot, given a desired acceleration or deceleration of the robotic system. These relationships were displayed in Figures (5), (7), and (8) in the Appendix. The results showed that 
there was a large negative impulse required to decelerate the system and a large positive impulse to accelerate the system. The stance time period (touchdown to liftoff) and the time where the virtual leg angle was greater than zero (touchdown to transition) were measured and analyzed.

The results showed that there was a greater amount of time from touchdown to transition while decelerating than when the model was at constant velocity. Also, there was a smaller amount of time from touchdown to transition while accelerating than when the model was at constant velocity. The relationship between impulse and touchdown to transition stance time yields the result of a larger virtual leg angle while decelerating and a smaller virtual leg angle while accelerating. The results were as expected and allow for a better understanding of the ground reaction forces needed and the angle of the leg at touchdown needed for accelerating and decelerating the quadruped system.

\section{CONCLUSION AND RECOMMENDATIONS}

This project studied the locomotion of quadruped robotic systems. A simulation program was used to analyze the robotic system's reaction in its environment. Data was recorded and then analyzed in MATLAB to produce graphical representations. The analysis gave a better understanding of what happened while the robot moved in the simulation environment.

The current trotting algorithm used in the simulation environment only allowed for accelerations and decelerations no greater than $\pm 0.25 \mathrm{~m} / \mathrm{s}^{2}$ per step. The results presented here give a better understanding of the ground reaction forces and touchdown angle required for the high speed trot of the quadruped system. The system decelerates by impacting the ground with a leg angle at touchdown larger than at acceleration and applying a negative impulse from time of 
Undergraduate Journal of M athematical M odeling: One +Two, Vol. 2, Iss. 2 [2010], Art. 10

touchdown to transition. In contrast, the system accelerates by making touchdown with a smaller leg angle and larger positive impulse from transition to liftoff.

Further research would be interesting to note the relationship between the locomotion of straight line trotting versus turning while trotting, as well as analyzing the trot on uneven terrain. 


\section{NOMENCLATURE}

\begin{tabular}{|clc|}
\hline Symbol & Meaning & Units \\
\hline $\boldsymbol{I}$ & Impluse & $\mathrm{kg} \cdot \mathrm{m}$ \\
\hline $\boldsymbol{p}$ & Momentum & $\mathrm{kg} \cdot \mathrm{m} / \mathrm{s}$ \\
\hline $\boldsymbol{m}$ & Mass & $\mathrm{kg}$ \\
\hline $\boldsymbol{v}$ & Velocity & $\mathrm{m} / \mathrm{s}$ \\
\hline
\end{tabular}

\section{REFERENCES}

Larson, Ron, Robert Hostetler, and Bruce Edwards. Calculus Early Transcendental Functions. 4th ed. Boston, MA: Houghton Mifflin Company, 2007. Print.

Palmer III, Luther R. "Intelligent Control and Force Redistribution for a High-Speed Quadruped Trot." Diss. The Ohio State University, 2007. Journal of Intelligent Robotic Systems 58.1 (2009): 47-68. Print.

Serway, Raymond A., and John W. Jewett. Physics for Scientists and Engineers. Belmont, CA: Thomson-Brooks/Cole, 2008. Print. 


\section{APPENDIX A - COMPUTER CODE}

\section{SIMULATION CODING:}

(Note that ' $\stackrel{\circ}{\circ}$ ' indicates a comment.)

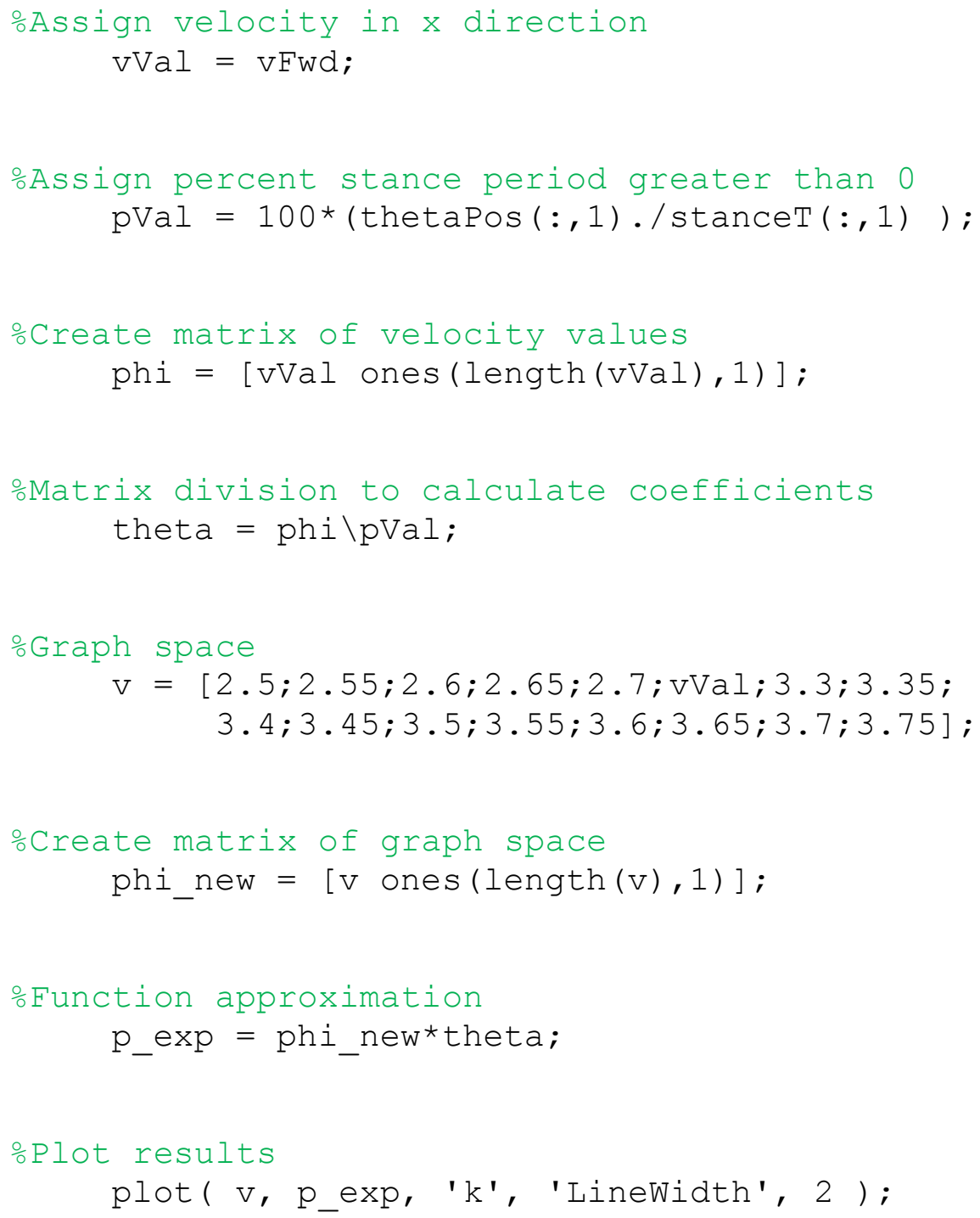




\section{APPENDIX B - FIGURES}

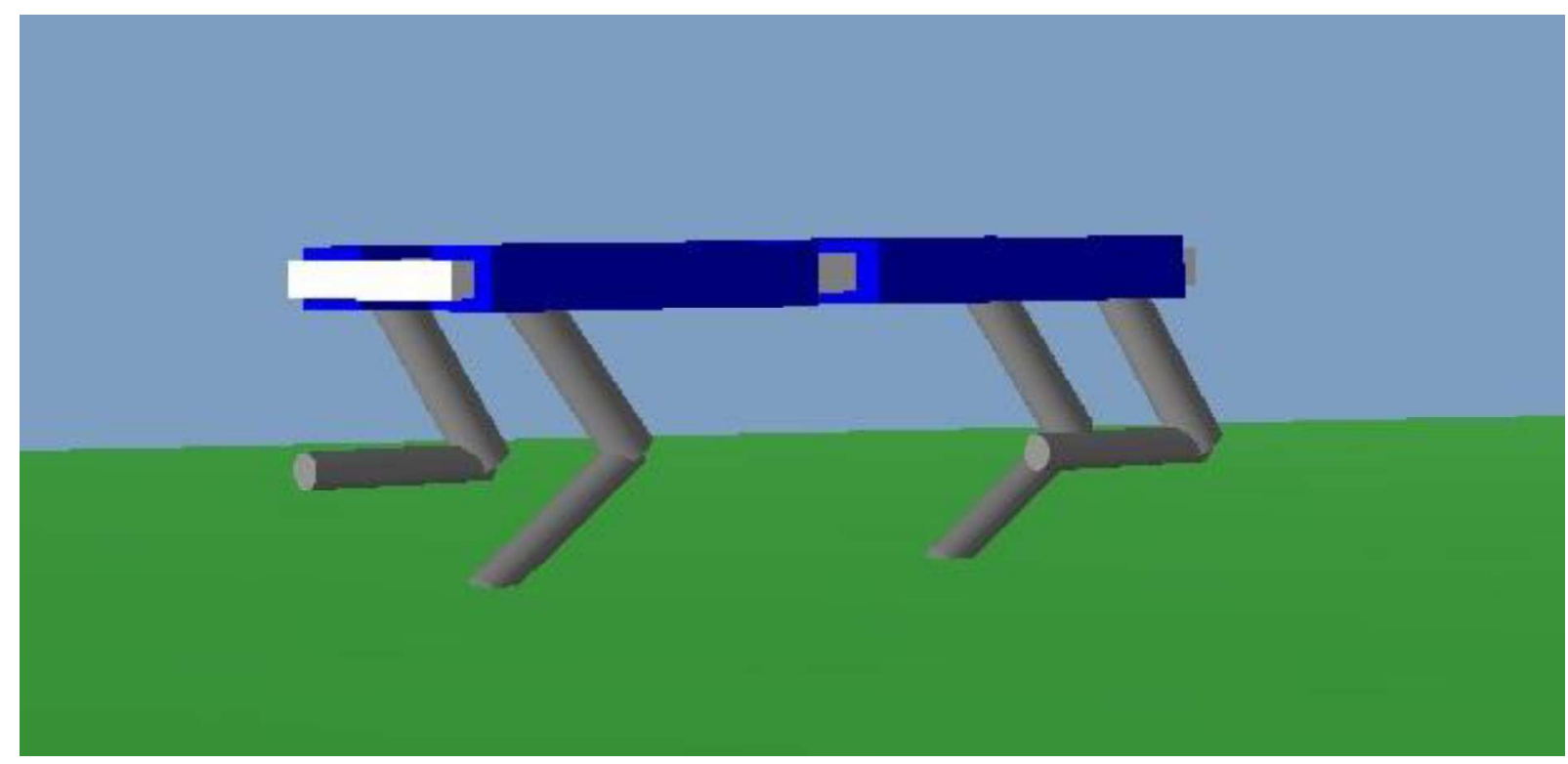

Figure (1): Shown above is the quadruped robotic system in the simulation environment. 


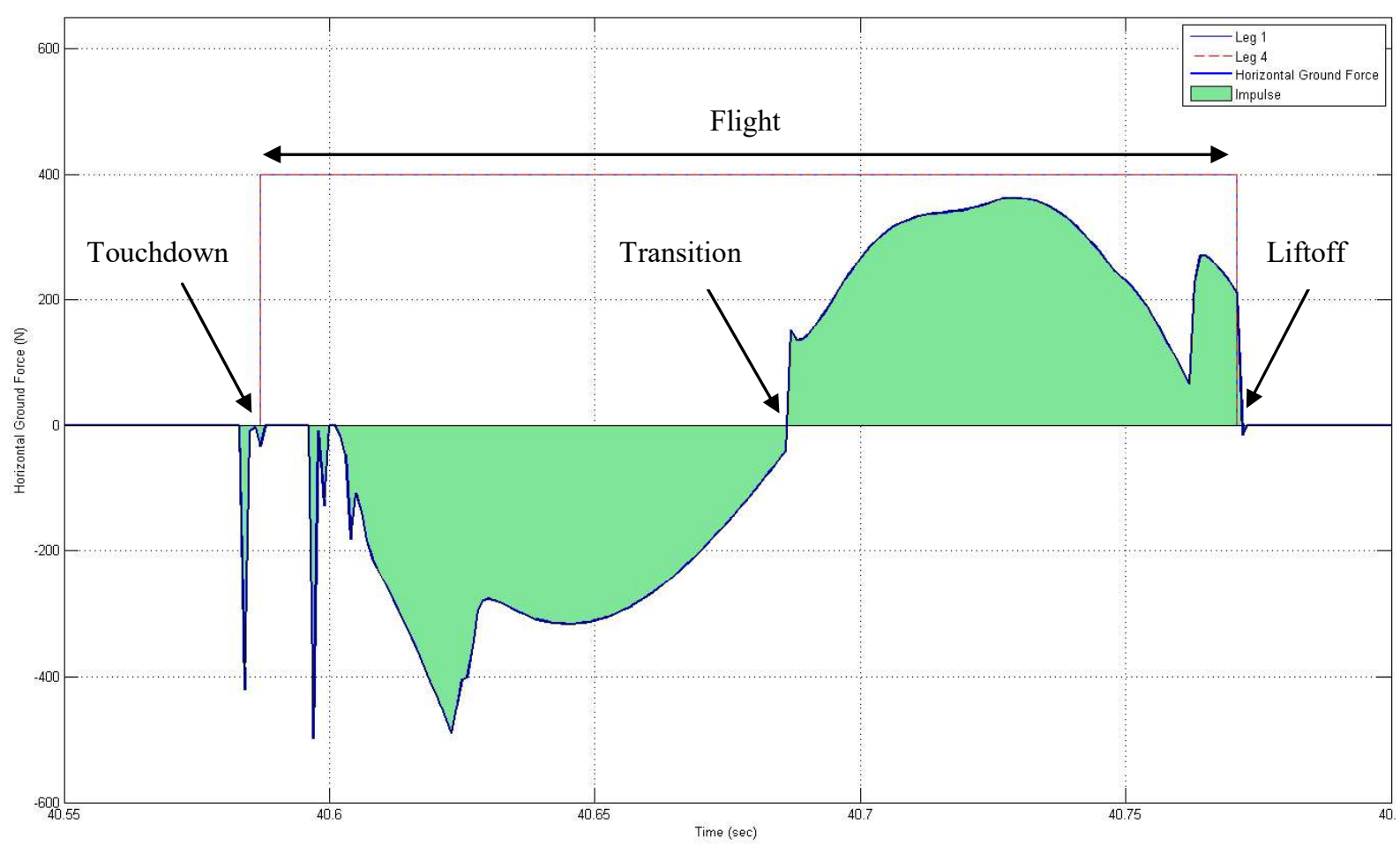

Figure (2): Shown above is a graph of the leg phases, horizontal ground force, and impulse. In this case, the robot travelled at a constant $3 \mathrm{~m} / \mathrm{s}$. The leading edge of the red and blue dashed line represents the touchdown of leg 1 and 4 and the trailing edge represents the liftoff. The thick navy blue line represents the horizontal ground force experienced at the given time step and the area under the curve (shaded green) represents the impulse.

Remark: The transition refers to the moment where the leg is orthogonal to the body. Notice the area under the curve to the left and right of the transition were relatively equal. 


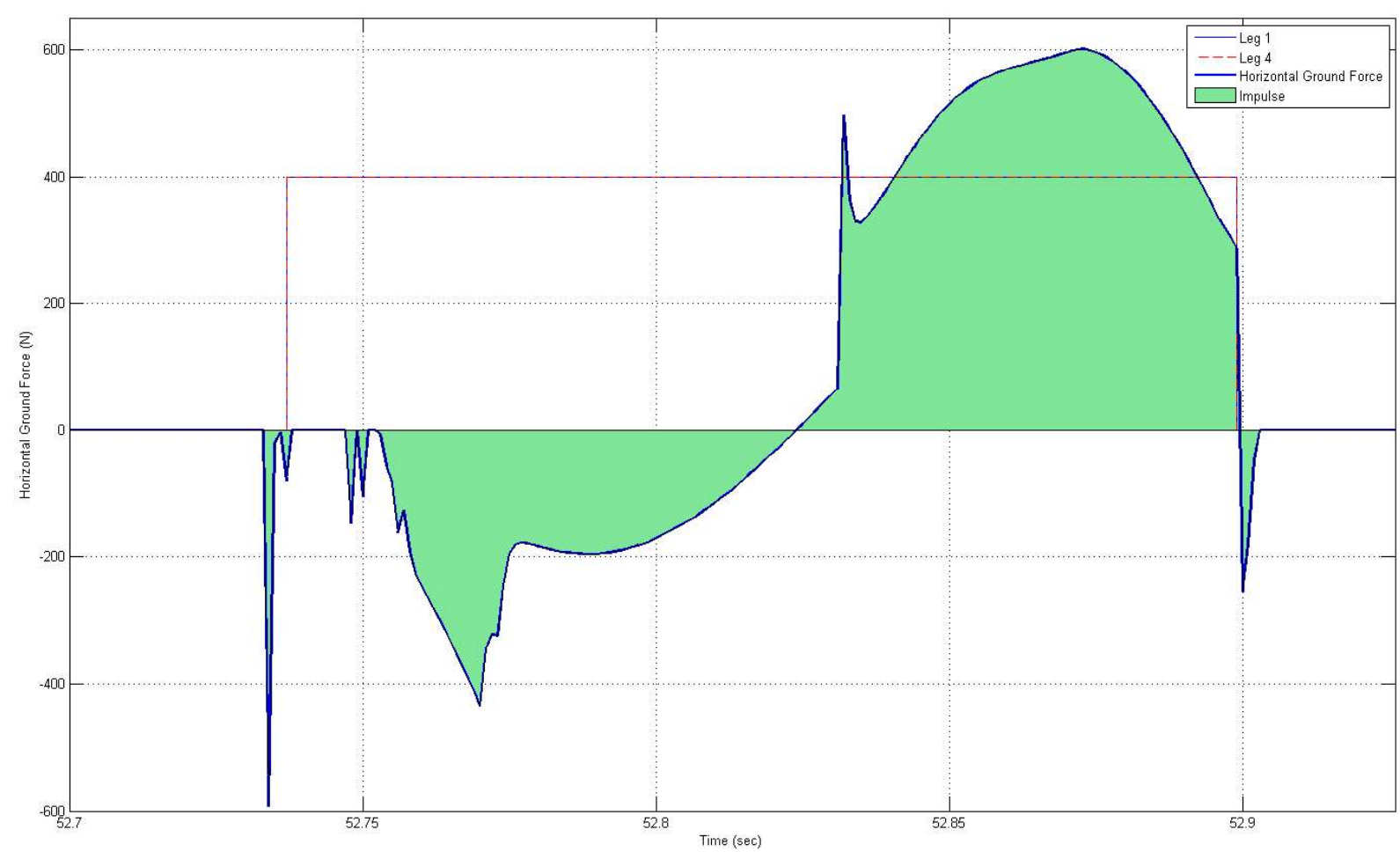

Figure (3): Shown above is a graph of the leg phases, horizontal ground force, and impulse.

Here, the robot accelerated from 3 to $3.25 \mathrm{~m} / \mathrm{s}$ in one step. The graphical description of Figure (2) also applies here.

Remark: Notice the area under the curve to the left of the transition was less than the right. This occurred because a greater force applied at liftoff was needed to accelerate the quadruped from 3 to $3.25 \mathrm{~m} / \mathrm{s}$. 


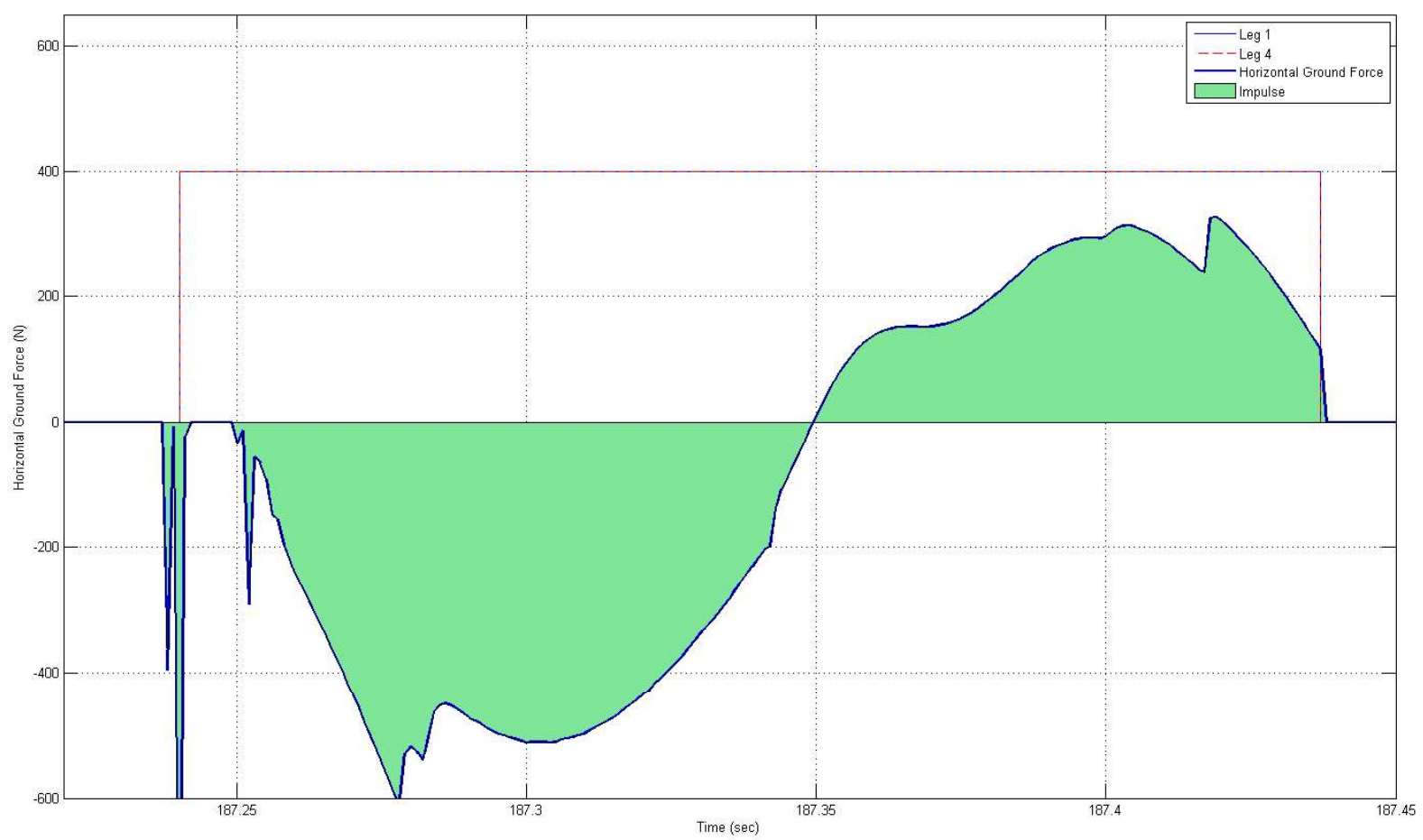

Figure (4): Shown above is a graph of the leg phases, horizontal ground force, and impulse. In this case, the robot decelerated from 3 to $2.75 \mathrm{~m} / \mathrm{s}$ in one step. The graphical description of figure (2) applies.

Remark: Notice the area under the curve to the left of the transition was more than the right. This occurred because a greater force applied at touchdown was needed to decelerate the quadruped from 3 to $2.75 \mathrm{~m} / \mathrm{s}$. 


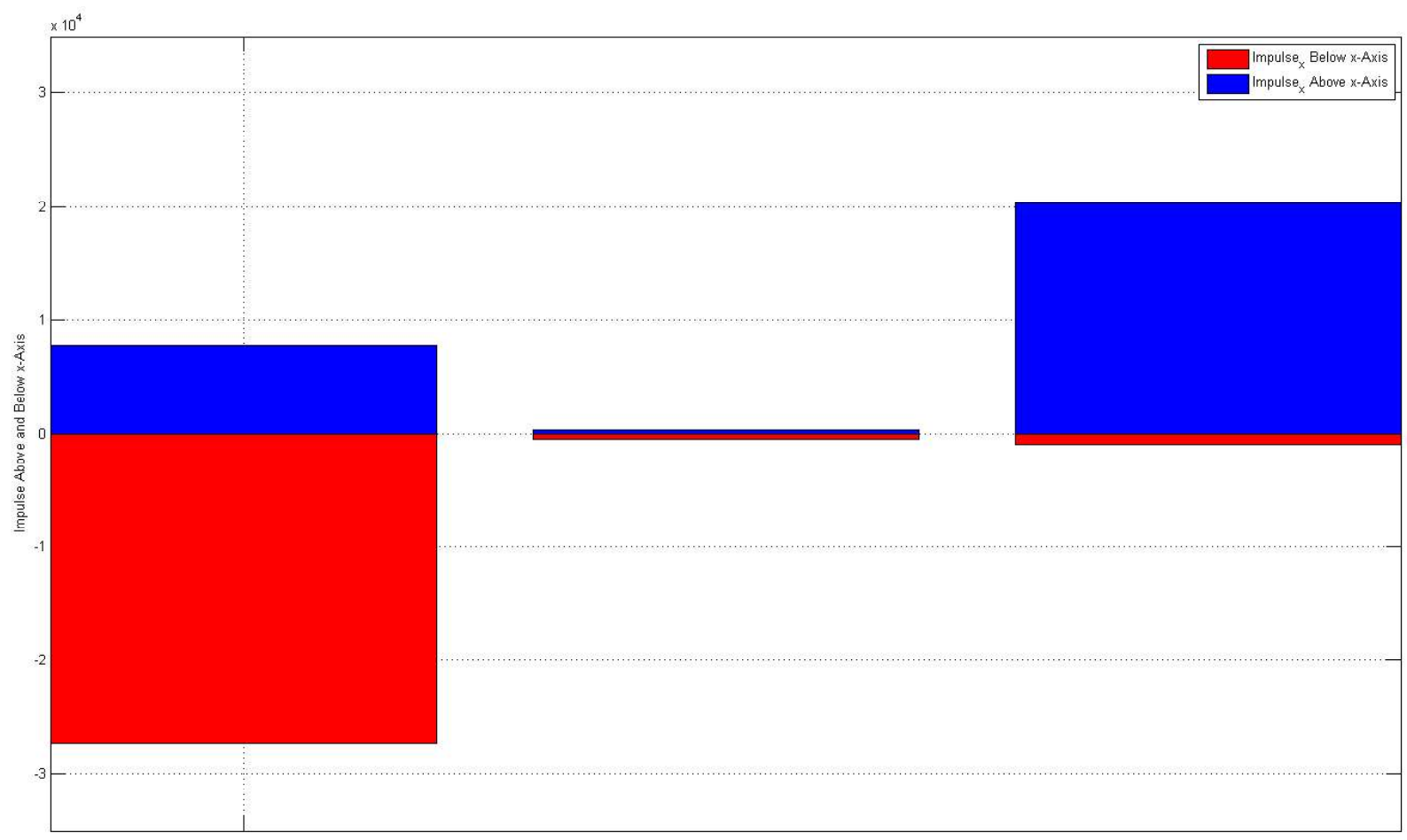

Figure (5): Shown above is a bar graph of the impulse in the $x$-direction. The red bar is the impulse below the $x$-axis and the blue bar is the impulse above the $x$-axis.

Remark: The large red area below the $\mathrm{x}$-axis on the far left graph represents the negative impulse needed to decrease the robot's velocity from $3 \mathrm{~m} / \mathrm{s}$ to $2.75 \mathrm{~m} / \mathrm{s}$. The middle graph represents the robot traveling at constant velocity; notice the small, equal areas both above and below the x-axis. The large blue area above the $\mathrm{x}$-axis on the far right graph indicates the large positive impulse needed to accelerate the robot from $3 \mathrm{~m} / \mathrm{s}$ to $3.25 \mathrm{~m} / \mathrm{s}$. 


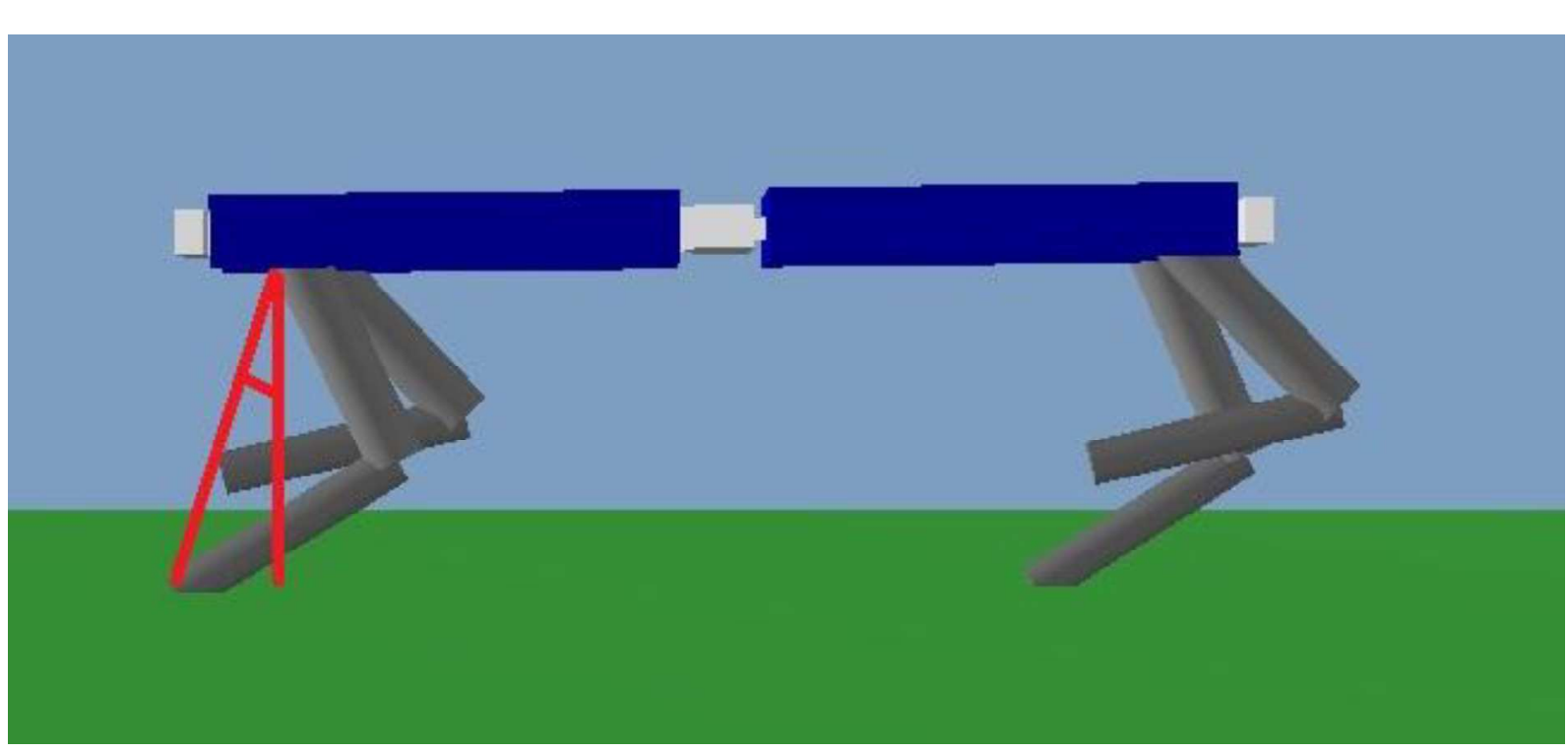

Figure (6): The virtual leg angle was measured from the orthogonal vector whose origin was at the hip. As the robot moved from right to left, the angle decreased to zero (transition), and then became negative until liftoff. 


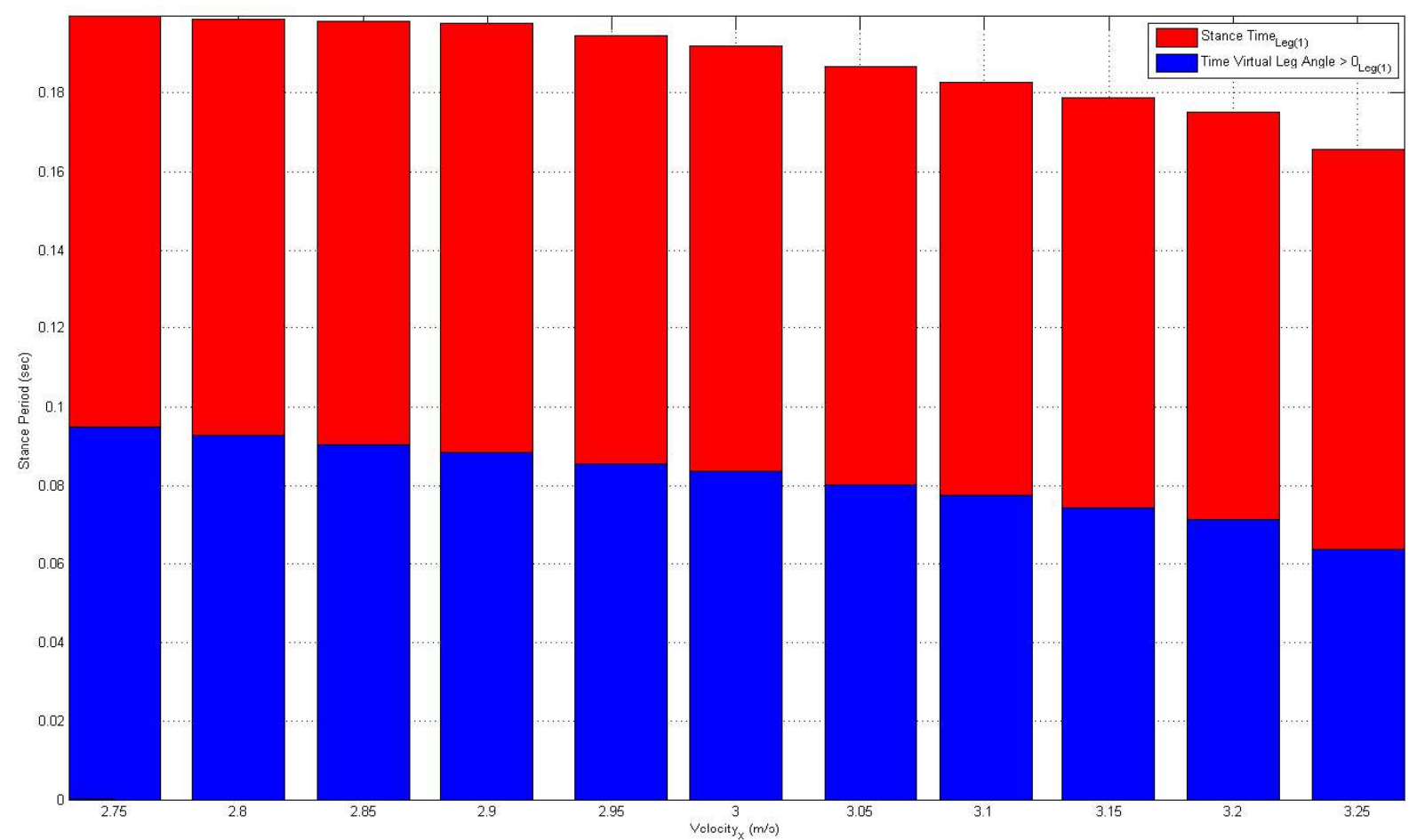

Figure (7): Shown above is a bar graph of total stance period (red) and the stance period that the leg angle was greater than zero (blue). This representation verified that the leg position at touchdown, while accelerating, decreased. This indicated that the angle required at touchdown was less than when traveling at constant velocity. It also verified that the leg position at touchdown, while decelerating, increased. This showed that the angle required at touchdown was greater than when traveling at constant velocity. 


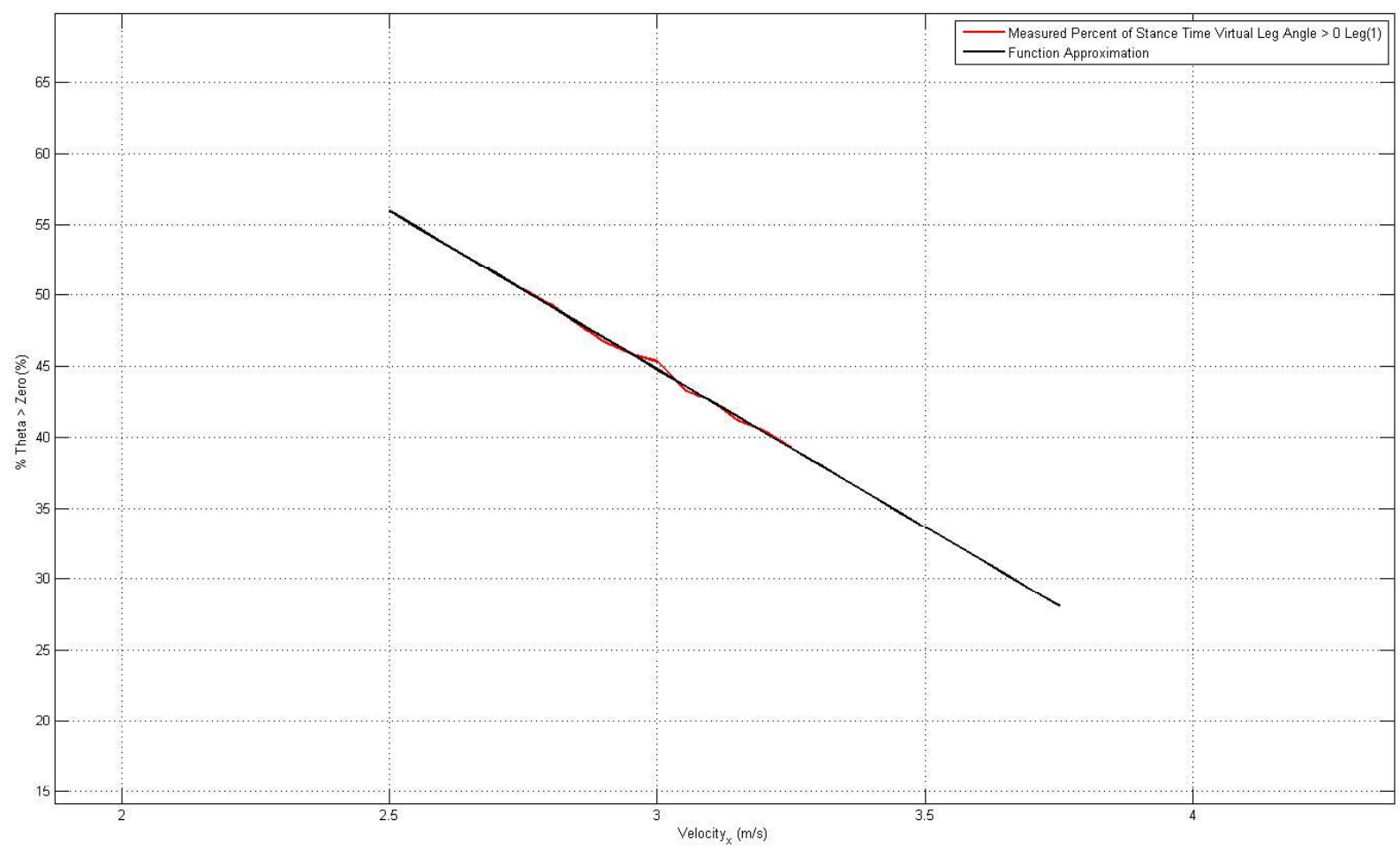

Figure (8): Shown above is the percent of stance time that the virtual leg angle is greater than zero. This directly correlated to the size of the angle at touchdown and the impulse required to accelerate or to decelerate the system. The red line depicts the measured values and the black line is the function approximation. 